\title{
The Effects of Social Interaction and Psychological Bias on Trading Behavior: Evidence from a Laboratory Experiment
}

\author{
Chi Ming Ho \\ Department of Finance, Southern Taiwan University of Science and Technology, Taiwan \\ Email: hcmccu@gmail.com,z0q@stust.edu.tw
}

How to cite this paper: Ho, C.M. (2018) The Effects of Social Interaction and Psychological Bias on Trading Behavior: Evidence from a Laboratory Experiment. Journal of Mathematical Finance, 8, 178-196. https://doi.org/10.4236/jmf.2018.81014

Received: January 12, 2018

Accepted: February 25, 2018

Published: February 28, 2018

Copyright $\odot 2018$ by author and Scientific Research Publishing Inc. This work is licensed under the Creative Commons Attribution International License (CC BY 4.0).

http://creativecommons.org/licenses/by/4.0/

Open Access

\begin{abstract}
This paper details an experiment designed to explore the trading behaviors of investors that result from psychological biases and social interactions. In total, 88 investors were tracked for 6 months and 40,795 transactions were recorded. The research conducted an experimental survey and estimated a system analysis model to generate several important conclusions. First, the degree of regret bias and the disposition effects are unrelated, probably because the professional training of investors and the disposition effects are not significantly related. Second, if investors are affected by contradictions arising from their decisions, then the likelihood that they will sell a stock will decrease as the investor relationships in the community improve and the regret bias increases. Third, male investors prefer to trade derivatives, and even after controlling for the degree of regret bias, this preference is still significant.
\end{abstract}

\section{Keywords}

Asset Allocation, Contradictory Decisions, Experimental Finance, Social Relationships, Regret Bias, Trading Behavior

\section{Introduction}

Understanding investors' trading behaviors is a common focus for both the financial industry and financial economic research. Many factors that affect investor trading have been previously identified, such as the use of momentum strategies for buying or selling securities [1] [2] and asset allocation, which is a strategy that is frequently recommended by the investor community [3] [4] [5] [6]. Although a trader's own attitudes, relationships and risk perceptions are also important factors that influence trading [7] [8] [9] [10], these factors have a 
greater effect on personal finances. The relationships among these variables and the impacts of their interactions on investors' trading behaviors and asset allocation are interesting but difficult to study.

A person's mental state is often inscrutable. People's ideas are difficult to predict, and it is these ideas that affect their investment behaviors [11]. The most common example is regret bias. Kahneman and Tversky used prospect theory to explain the impact of regret bias on investment behavior [12]. This relationship between regret bias and investment behavior has also been supported by other studies [13] [14] [15] [16]. However, certain studies only utilized qualitative reasoning and did not employ transaction data, which are needed to verify the robustness of the conclusions. This paper is based on the virtual transactions of investors and the results of a matching questionnaire. The first objective of this study was to demonstrate a relationship between the regret bias effect and the disposition effect in order to explore the influence of psychological bias on transaction behavior.

In addition to regret bias, investors are also affected by their environments, which influence their trading behavior; herding behavior is one example where trading activities are affected by the environment [3] [6] [17]. People are social animals and establish their own social relationships. Themes of common interest and opportunities to communicate directly cause investors to more readily listen to others' suggestions and trade stocks [7] [18] [19] [20]. However, people have varying degrees of psychological bias, and not all people have the same social relationships. Therefore, if members of a group have differing opinions and ideas, contradictions will arise in the decision-making process, and their investment behaviors will change. For example, if an investor is motivated by regret bias to sell a profitable stock, but the community believes that the stock is promising and plans to buy shares of the stock, the investor may choose to sell his or her shares or continue to hold onto the stock. This paper argues that a stronger interaction effect corresponds to a higher probability that a contradiction will arise from the investor's decision which, in turn, can delay the investor's decision to sell the stock. A similar discussion has not been previously published, although this argument can explain investors' decisions to buy instead of sell a stock that has a strong reference value. The second objective of this article was to explain this phenomenon.

Finally, the trading behaviors of investors are also affected by the individuals' characteristics, such as their emotional responses and abilities to interpret market information [21]. Other characteristics include gender, age, stress, experience and relevant external stimuli [8] [22] [23]. Several previous studies have assessed the effect of gender on trading behavior [24] [25] [26]. These researchers believed that because women have a lower degree of overconfidence, female investors are more careful investors than men [27]. In addition, past research has indicated that women have a high degree of perceived risk aversion [9] [10], their risk attitude is more negative [28] and their asset allocation is relatively conserv- 
ative [29]. For these reasons, we argue that male investors allocate more of their capital to derivatives. The final objective of this paper was to confirm that asset allocation is affected by the characteristics of individual investors.

This study had several key objectives and makes a number of contributions. The primary aim was to create a model to analyze the impact of interactions between investor psychology, relationships, gender and variables related to trading behavior. The subjects' answers may have differed from the actual situations due to the influence of psychological bias. For example, the respondents may have forgotten the results of past transactions; additionally, they may have avoided acknowledging their own investment mistakes, and have provided random answers. Thus, the credibility of the conclusions requires further improvement. This paper examined a large sample and analyzed the subjects via the content of a matching questionnaire; therefore, the results are robust. In addition to the disposition effect, the impact of the investors' characteristics on asset adjustments was observed. These effects include changes in the selling and allocation of derivatives. The above conclusions may strengthen weaknesses in poorly studied areas of similar research and may also be used as a reference in personal finance and risk management literature.

This complete analysis revealed several important findings. First, regret bias and the disposition effect have no statistically significant relationship. Second, stronger regret biases and stronger social relationships correspond to fewer stocks sold by investors. Third, after controlling for regret bias, we found that male investors allocate a greater amount of capital to derivatives than do female investors. This paper is organized as follows: Section I includes the introduction and provides the statement of purpose for this study; Section II presents the theory and assumptions; Section III reviews the methods of the study, including the choice of data, the experimental design and the model; Section IV contains the empirical analysis and the system estimation model used to perform the data analysis. Finally, the last section provides conclusions and recommendations and discusses the results.

\section{Theory and Hypotheses}

This section reviews the relationship between the variables and specific theoretical studies. Additionally, this section establishes the hypotheses that served as the basis for the empirical analysis.

Because investors who buy securities are afraid of loss, they often sell off a portion of their profitable stocks, even if these stocks have not yet generated high profits. This behavior is driven by the fear of a sudden stock price reversal. Investors fear incurring losses, since this could generate serious psychological regrets. Conversely, stock investors may remain hopeful that they can "turn around" stocks that are gradually losing money, thus avoiding an acknowledgment of their decision-making errors [12]. Regret bias inspires investors to adopt a "sell surpluses and hold losses" mentality. It causes investors to sell their 
profitable stocks, regardless of the losses in securities, to avoid the portfolio becoming unbalanced and the risk becoming high. Previous studies have called such investment behavior "the disposition effect" [30]. Many studies have confirmed the existence of such irrational investor behavior [14] [31] [32] [33] [34].

Goo et al. used confirmatory factor analysis to assess investors in the Taiwan market [15]. Based on the questionnaires of Shefrin and Statman, and Muermann, Wise and Jacqueline, the disposition effect was found to be related to individual investors' desires to both avoid regret and enhance their self-esteem (i.e. they seek pride) [30] [35]. Chong used the example of Malaysia's initial public offerings (IPO) market with Shiller's regret theory to explain the phenomenon of price reversal in IPOs [14] [36]. Chong found that the disposition effect of investors is related to the extent to which they fear regret [14]. Based on prospect theory, Goo et al. and Chong argued that regret bias is closely related to the disposition effect [14] [15]. Thus, we predicted that a higher level of investors' regret bias would be associated with a clearer manifestation of the investors' disposition effect. These two factors have a significant and positive correlation. Therefore, we have established Hypothesis 1 to address the above corollary.

Hypothesis 1: In the context of performance concerns, there is a clear and positive relationship between regret bias and the disposition effect.

People are social animals, and their decision-making processes are often influenced by other people. In financial literature, the best-known example of this influence is the herd effect [3] [4] [5]. Maital et al. believed that if the herd effect were to become a societal trend, the future development of the stock market would be difficult to control, and a price collapse would occur [20]. Thus, as the herd effect of investors becomes more prominent, the stock market is subjected to an increased level of distortion.

As the investor community relationship improves and social interactions become stronger, the chances that direct communication will take place, that investors will listen to the views of others or that investors will adjust their original stock portfolios, will improve [17] [37]. All this leads to a more prominent herd effect [7] [20]. Because of regret bias, investors are prone to making decisions that generate future contradictions and consequently reduce the occurrence of sell orders. Investors who have good social relationships suffer from regret bias because they are more likely to listen to the views of the public when trading stocks. When buying securities, investors may rely on their own views or the recommendations of market investors. In contrast, investors will consider selling their stocks based on one or more of four scenarios. First, investors will sell a profitable stock if most people have a negative view of its future profitability. Second, in the opposite case, investors may want to sell a profitable stock, but other people may hold a positive view of the stock. In this case, investors will suffer from internal conflict and will not know whether to sell or to continue to hold onto the stock. Third, investors will continue to hold onto a declining stock because of the impact of regret bias when other people hold a negative view of the stock's future price. In this case, contradictions will arise in the investors' de- 
cision-making process, and investors will not be able to determine whether to sell or continue holding onto their shares. Finally, if a stock is declining but the public is optimistic about its future trend, investors are likely to buy more shares of the stock because of the combined impact of regret bias and the herd effect. Although the stock is losing money, investors will continue to hold onto the stock. For these reasons, investors who suffer from a high degree of regret and have better relationships with the investment community will lose touch with their original reasoning because of the interaction between these two effects. The investor's decision-making process will suffer from contradictions that prompt them to distance themselves from their original rationale. Because of their psychological hesitation, they will decrease their number of sell orders, and this will significantly reduce the probability of selling the stock. ${ }^{1}$ In other words, the investor's selling rate should show a downward trend due to the interaction between these two psychological biases. Accordingly, we propose Hypothesis 2.

Hypothesis 2: Investors with a higher degree of regret bias and better relationships within the investment community will sell their stocks at a lower rate than other investors because of the effects of decision-making conflicts.

Maital et al. and Tauni et al. indicated that the irrational behavior of investors is also influenced by their personality traits, emotional reactions and ability to interpret the impact of market information [21] [23]. Shefrin found that investors' irrational behaviors are related to gender, age, experience and external stimuli [8]. Deaux and Emswiller, and Beyer and Bowden focused on the impact of gender on investment behavior and suggested that compared to female investors, male traders are more likely to exhibit overconfidence [24] [26]. The same is also true in corporate finance, where women managers are more careful when making decisions because they tend to exhibit less overconfidence than men [27]. In addition, in a review of financial risk preferences and financial management areas (i.e. financial domains), Vlaev et al. determined that women are relatively more risk-averse than men [10]. Similarly, in a questionnaire-based study of Turkish financial advisers, Tutek et al. noted that female financial advisers, at the same risk level, could offer more valuable advice on controlling risk because women are more risk-averse [8]. Men and women have different levels of risk aversion and different risk attitudes. Women use asset allocation strategies that are more conservative than those of the men [29]. For these reasons, Arano et al. argued that because men have a higher degree of overconfidence and a lower level of risk aversion than women do, men are more likely to be tempted to seek

${ }^{1}$ With respect to the contradictions arising from the decision-making process, investors will sell their stocks in the first scenario. In the second scenario, although the number of sell orders is reduced, there is still the possibility of selling the stock, and the probability of each of the hypotheses is $1 / 2$. The third scenario is also uncertain; there is a possibility that the stock will not be sold. The probability of each of the hypotheses is again $1 / 2$. The fourth scenario is to not sell the stock; i.e. when considering all of the criteria and the equal distribution of the hypotheses, the probability of selling stock is $1 / 2(1 / 4+1 / 4 \times 1 / 2+1 / 4 \times 1 / 2)$. Compared to the original conditions, the probability of an investor selling his or her securities decreased from 1 to $1 / 2$, which is clearly a large decrease. According to this reasoning, the proportion of sell positions among all trades will decrease. 
opportunities for extreme profits and to allocate capital to derivatives [29]. We offer Hypothesis 3 to confirm the above assumption.

Hypothesis 3: On average, male investors prefer to trade derivatives, even with control for different levels of regret bias.

\section{Data and Research Methods}

This section describes the objectives, data collection processes and models of the study. The detailed discussion of the model also includes the measurements of the variables, the experimental design and the measurement methods. In this section, we describe the construction of the models of regret bias, social relationships, gender and transactions.

In this study, Taiwanese investors in emerging Asian markets were used as the subjects. Because the investors' transaction records are protected by local laws and are not readily available, we used other financial data for the analysis. This data collection process is similar to the methods used by Oehler et al., Weber and Camerer, and Chui [16] [38] [39]. The subjects were students from the finance department of a university in Taiwan. After issuing 101 questionnaires, we collected 93 responses. We then checked the trading data from the period of study and excluded invalid questionnaires and unreasonable trading practices. We obtained a total of 88 valid questionnaires and recorded 40,795 transactions.

\subsection{Source}

Concurrent with the questionnaire study, the respondents participated in a virtual trading competition. The investment period was 6 months, and an investment amount of NT\$5 million was granted (In the Taiwan Stock Market, only ordinary investors are considered, and securities dealers are given a credit line ranging from NT\$3 million to NT\$5 million. Therefore, to simulate an actual trading situation, the students were given a balance of only NT\$5 million), which could be traded for financial products, including stocks, futures and options. The students were also allowed to engage in credit transactions. This design is in accordance with the general conditions in which investors operate. Thus, the experimental data closely resembled the content of actual transactions. The positions held and the price changes in virtual trading and actual trading are no different. A system vendor was then asked to provide a field audit of the digital processing and check for accuracy. Transactions with unusual numbers were removed. On average, there were 463 transactions per person during the period of the study.

\subsection{Research Methods}

\subsubsection{Measurement of the Variables}

This study used six variables: regret bias (RB), the disposition effect (DE), social relationships (SR), the ratio of sell orders (TO), gender (DUMMY) and asset allocation ratio (AL). The RB, SR and DUMMY data were obtained from the sur- 
vey, whereas the $\mathrm{DE}, \mathrm{TO}$ and $\mathrm{AL}$ data were calculated from the experimental data. The measure of regret bias is based on Pompian's diagnostic questionnaire [40]. This measurement is often used in the industry and therefore has good reliability and validity. There were three questions in the questionnaire. Each question had three answers, and the answers were sorted based on the magnitude of regret bias. In this paper, the answers were expressed as points (5 points, 3 points and 1 point). The first answer ( 5 points) indicates the greatest amount of investor regret bias. Therefore, a higher average total score corresponded to a greater extent of regret bias. There were four questions regarding social relationships. Three questions referred to Hong et al.'s questionnaire, whereas the last question was an amendment that measured the increase in the density of the investors' social networks [7]. There were three options for each question. The investors who selected the first option (5 points) had stronger social relationships. Therefore, higher average scores were associated with investors' stronger social relationships. Gender was a dummy variable with a value of 1 for male and 0 for female. The disposition effect was calculated by referring to Weber and Camerer's study, which used the a coefficient as a proxy for the disposition effect; $\alpha$ was calculated according to the following equation: (the number of shares sold at a profit - the number of shares sold at a loss)/(the number of shares sold at a profit + the number of shares sold at a loss) [38]. When the $\alpha$ coefficient was significantly greater than 0 , the investors exhibited the disposition effect. The ratio of sell order values was calculated by dividing the number of shares sold by the total transaction amount. A higher ratio of sell order values corresponded to a higher proportion of sell orders [41]. Finally, the paper calculated the asset allocation ratio values by recording the number of derivatives, which accounted for the weight of all financial products in each portfolio [42] [43]. A higher asset allocation ratio corresponds to a larger proportion of capital allocated to derivatives.

\subsubsection{Design of the Experiments}

In this study, each investor was assigned a number ranging from 1 to 88 , and then the corresponding virtual transactions were analyzed. First, the data for the six variables (RB, DE, SR, TO, DUMMY and $\mathrm{AL}$ ) were uploaded for each investor. The RB, SR and DUMMY data were derived from the questionnaire, whereas the $\mathrm{DE}, \mathrm{TO}$ and $\mathrm{AL}$ values were calculated using data from the virtual transactions. Second, the subjects were divided into four groups based on the extent of regret bias. The upper $1 / 4$ of the samples had the least degree of regret bias, and the lower 1/4 of the sample had the greatest degree of regret bias. Each group had approximately 22 investors. Similarly, the respondents were divided based on the quality of their social relationships. Third, the disposition effects of the groups were divided based on regret bias to determine whether the differences among the groups were significant. Next, the ratio of sell orders was calculated for the groups with the highest degree of regret bias and the strongest social relationships. This ratio was then compared with the ratio of sell orders of 
the groups with the least degree of regret bias and with the least developed social relationships to evaluate the differences between the two groups. Finally, in the regret bias groups, the male and female investors were separated and the ratio of asset allocation was calculated for the two groups to determine whether there were any differences between the groups.

\subsubsection{System Estimates Model}

To determine the robustness of the results, this paper used an alternative set of equations, the weighted least squares (WLS). The advantage of this approach is that the system equations can incorporate all of the variables into the equation, which has full use of the other information from the equations, to increase the explanatory power of this equation. For example, gender may have an impact on the disposition effect, and the ratio of sell orders (turnover rate) may also affect the disposition effect [32]. Additionally, because the herd effect will result in irrational trading behavior [4], social relationships may also affect the disposition effect. Therefore, the system equations were used to link the multiple effects. The variables are shown in Equation (1) below. The variable definitions are described in Section 3.3.1. The variables were multiplied to represent the interactive effect; $\alpha$ is the intercept coefficient and $\beta_{i}$ is the coefficient for the individual variables. The regression coefficient was estimated in Equation (2) and $\varepsilon_{i}$ represents the equation residuals [44].

$$
\begin{gathered}
\mathrm{DE}_{i}=\alpha+\beta_{1} \mathrm{RB}_{i}+\varepsilon_{i} \\
\mathrm{TO}_{i}=\alpha+\beta_{1} \mathrm{RB}_{i}+\beta_{2} \mathrm{SR}_{i}+\beta_{3} \mathrm{RB}_{i} \times \mathrm{SR}_{i}+\varepsilon_{i} \\
\mathrm{AL}_{i}=\alpha+\beta_{1} \mathrm{RB}_{i}+\beta_{2} \mathrm{DUMMY}_{i}+\beta_{3} \mathrm{RB}_{i} \times \mathrm{DUMMY}_{i}+\varepsilon_{i} \\
B_{i}=\left(X^{\prime} \Omega^{-1} X\right)^{-1} X^{\prime} \Omega^{-1} y, \Omega=\left[\begin{array}{ccccc}
\omega_{1} & 0 & 0 & \cdots & 0 \\
0 & \omega_{2} & 0 & \cdots & 0 \\
0 & 0 & \omega_{3} & \cdots & 0 \\
\vdots & \vdots & \vdots & \ddots & \vdots \\
0 & 0 & 0 & \cdots & \omega_{n}
\end{array}\right], \omega_{i}=\operatorname{Var}\left(\varepsilon_{i}\right) / \sigma^{2}
\end{gathered}
$$

\section{Results and Discussion}

This section contains the empirical analysis, which includes the descriptive statistics, hypothesis t-test and robustness analysis for the estimated models.

\subsection{Descriptive Statistical Analyses}

Six variables were used in this study: DE, RB, SR, TO, DUMMY and AL. Table 1 presents the descriptive statistics of the variables, including the number of individuals $(\mathrm{N})$, mean (Mean), median (Median), minimum (Min), maximum (Max) and standard deviation (Std). For example, the Mean of DE is -0.0577 , the Median is -0.0490 , the Max is 1 , the Min to -1 and the Std Dev is 0.4947 (Table 1). With the exception of the disposition effect, the averages of the other variables are all positive. In addition, based on the standard deviations, the regret bias 
Table 1. Descriptive statistics of the sample. This table presents descriptive statistics of the sample. The statistics include the number of individuals $(\mathrm{N})$, mean (Mean), median (Median), minimum (Min), maximum (Max) and standard deviation (Std).

\begin{tabular}{ccccccc}
\hline \multirow{2}{*}{ Variables } & \multicolumn{5}{c}{ Descriptive statistics } \\
\cline { 2 - 7 } & $\mathrm{N}$ & Mean & Median & Min & Max & Std \\
\hline DE & 88 & -0.0577 & -0.0490 & -1.0000 & 1.0000 & 0.4947 \\
RB & 88 & 3.2915 & 3.6667 & 1.0000 & 5.0000 & 1.1754 \\
SR & 88 & 2.8182 & 3.0000 & 1.0000 & 4.5000 & 0.7701 \\
TO & 88 & 0.3853 & 0.3871 & 0.0580 & 0.7467 & 0.1467 \\
AL & 88 & 0.2378 & 0.0772 & 0.0000 & 1.0000 & 0.3332 \\
\hline
\end{tabular}

showed the largest variability among the investors, whereas the difference in the ratio of sell orders was the smallest. Additional detailed data are shown in Table 1.

\subsection{Hypothesis Testing}

\subsubsection{Verification of the Relationship between Regret Bias and the Disposition Effect}

To test Hypothesis 1, the impact of investors' regret bias on the disposition effect was evaluated. In other words, it was determined whether a positive relationship existed between the two variables. The results from the t-test analysis of the influence of regret bias on the disposition effect are shown in Table 2. This paper predicted that the difference in the average disposition effect between the lowest and the highest groups should be significant. However, the average DE value in the lowest regret bias group was -0.1049 , and the average DE value in the highest regret bias group was -0.0804 . Although the average difference was 0.0245 , the $\mathrm{t}$-value was not at the $10 \%$ significance level. Therefore, unlike the conclusions of Chong and Goo et al., the observations presented here do not support Hypothesis 1 [14] [15].

It was unclear why the regret bias effect showed a significant positive relationship with the disposition effect. Further analysis demonstrated that the coefficient of the disposition effect for all investors was -0.0577 (see Table 1). The $\mathrm{t}$-test showed that this relationship was not significantly greater than $0(\mathrm{t}=$ $-1.09374, p=0.2771)$. In other words, the disposition effect was not significant for any of the investors. In addition, because the students who constituted the samples were from the finance department of a Taiwanese university, and because these students may have been affected by the professional training they had undertaken, the students were less prone to engaging in irrational trading behavior. These two factors may explain the lack of support for our hypothesis. Although this study did not find significant support for the effect of regret bias on the disposition effect, when the data in Table 1 and Table 2 are compared, the variables still had economic implications [12]. Additionally, the investors generally had psychological biases $(\mathrm{RB}=3.2915)$. However, after undergoing 
Table 2. Results of the t-test of the impact of regret bias on the disposition effect. This table shows the results of the t-test for the differences between the highest and lowest regret bias $(\mathrm{RB})$ groups with respect to the mean impacts of regret bias on the disposition effect (DE).

\begin{tabular}{ccccc}
\hline & \multicolumn{4}{c}{ Statistics } \\
\cline { 2 - 5 } Variables & $\begin{array}{c}\text { Mean in lowest } \\
\text { regret bias group }(\mathrm{N}=22)\end{array}$ & $\begin{array}{c}\text { Mean in highest regret } \\
\text { bias group }(\mathrm{N}=22)\end{array}$ & $\begin{array}{c}\text { t-value of the } \\
\text { difference in the } \\
\text { averages }\end{array}$ & p-value \\
\hline $\mathrm{DE}$ & -0.1049 & -0.0804 & -0.1732 & 0.8634 \\
\hline
\end{tabular}

professional training, the investors were less likely to engage in irrational behavior $(\mathrm{DE}=-0.0577)$. This result is similar to the findings of Locke and Mann [45].

\subsubsection{Verification of the Impacts of Regret Bias and Social Relationships on Trading Behavior}

Hypothesis 2 was designed to verify that the investors with more regret bias and better social relationships lose touch with their original judgments due to contradictions that arise during their decision-making processes. As a result, these investors sell fewer shares of their stocks and thus reduce the number of their sell orders. In other words, this study intended to confirm that the average number of sell orders of the lowest group (in terms of both regret bias and social relationships) would be significantly higher than the average number of sell orders of the highest group. Table 3 provides the results of the t-test of sell orders for the different regret bias and social relationships groups. The average TO in the lowest group was 0.4482 , whereas the average TO in the highest group was 0.3642 . The difference in the average TO for the two groups was $0.084(t=$ $1.9813, \mathrm{p}=0.0559$ ), which was statistically significant at the $10 \%$ level; thus, Hypothesis 2 was supported.

Figure 1 shows that the negative effects of regret bias and community relationships have an inverse effect on the rate of sell orders. The implications of this result are two-fold. First, all of the stocks bought on the advice of a friend lost money. However, due to the impact of regret bias, investors were reluctant to sell their stocks. Therefore, the stock selling rate will be low. Conversely, the second implication is that the stock recommended by a friend might have the potential to increase in value in the future. Therefore, to obtain large profits, investors will not sell the stock, and the selling rate will be low. If the investors' sell rate declines and the overall market environment is poor (i.e. the stock market is falling), the stock cannot be sold at all. In this case, the supposition of Maital et al. will become reality [21].

\subsubsection{Verification of Assumptions Regarding Gender, Regret Bias and the Allocation of Derivative Assets}

Hypothesis 3 was tested to verify that investors who differ in gender and in their degrees of regret bias allocate capital to derivative assets in different ratios. In 


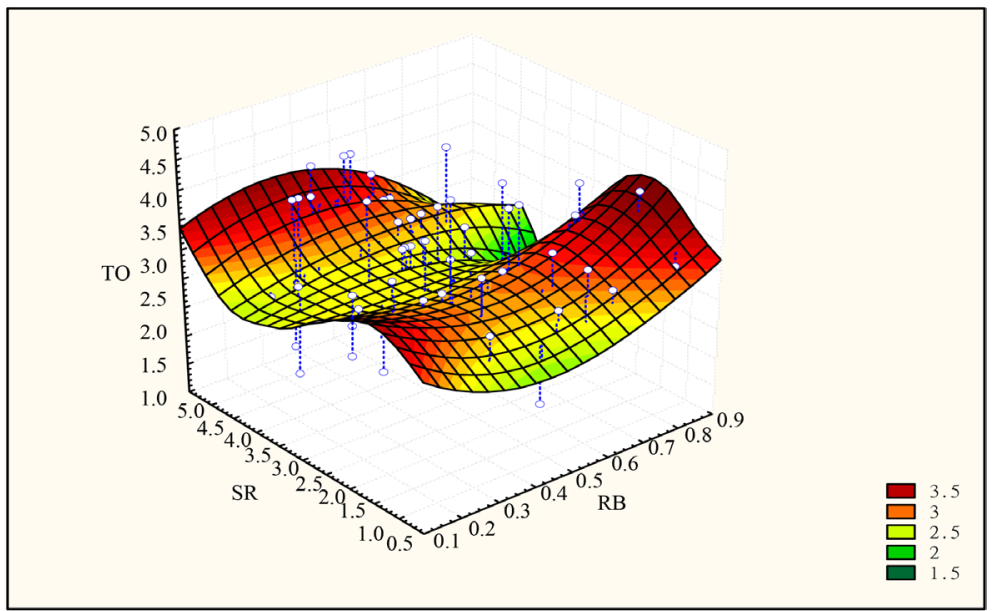

Figure 1. Surface chart of the ratio of sell orders as a function of regret bias and social relationships. The figure indicates the change in sell orders as a function of the investors' regret bias and social relationships.

Table 3. The t-test results for sell orders in groups with different levels of regret bias and types of social relationships. This table presents the t-test results for the mean differences in the rate of sell orders (TO) in the highest and lowest groups in terms of regret bias (RB) and social relationships (SR).

\begin{tabular}{|c|c|c|c|c|}
\hline \multirow[b]{2}{*}{ Variable } & \multicolumn{4}{|c|}{ Statistics } \\
\hline & $\begin{array}{l}\text { Average in the lowest regret } \\
\text { bias and community } \\
\text { relationship groups } \\
(\mathrm{N}=22)\end{array}$ & $\begin{array}{l}\text { Average in the highest regret } \\
\text { bias and community } \\
\text { relationship groups } \\
(\mathrm{N}=22)\end{array}$ & $\begin{array}{l}t \text {-value of the } \\
\text { difference in the } \\
\text { averages }\end{array}$ & $\mathrm{p}$-value \\
\hline TO & 0.4482 & 0.3642 & 1.9813 & 0.0559 \\
\hline
\end{tabular}

this study, men were assumed to have a higher degree of overconfidence, to be less risk-averse, to more likely take risks to generate profits and to be more likely to allocate capital to derivative assets compared to women. Table 4 presents the $t$-test results for the ratio of derivatives for the two genders. The data from the table show that the average ratio of derivative asset allocation for female investors was 0.19 , whereas the average ratio for the male investors was 0.3952 . The difference in average AL values between the two groups was $-0.2052(\mathrm{t}=$ $-2.5005, \mathrm{p}=0.0143$ ) and was statistically significant at the $5 \%$ confidence level. Thus, there is preliminary support for Hypothesis 3.

The samples were further divided into groups according to the degree of regret bias. We then analyzed the influence of gender on the ratio of derivative asset allocation. The method used here was similar to the methods used in 4.2.1 and 4.2.2. Table 5 presents data derived from the $t$-test of gender differences on the ratio of derivatives allocation in the lowest regret bias group. According to the table, the average value of the female investors' derivative asset allocation was 0.2690 , whereas the average value for the male investors was 0.7891 . The difference in the average AL between the two groups was $-0.5201(t=-2.6966, p$ $=0.0143)$, which is statistically significant at the $5 \%$ confidence level. Table 8 
Table 4. Results of t-tests of the impact of gender on the ratio of derivative asset allocation. This table groups the respondents by gender (DUMMY) and by the derivative asset allocation ratio $(\mathrm{AL})$.

\begin{tabular}{ccccc}
\hline \multirow{2}{*}{ Variable } & \multicolumn{4}{c}{ Statistics } \\
\cline { 2 - 5 } & $\begin{array}{c}\text { Female group average } \\
(\mathrm{N}=68)\end{array}$ & $\begin{array}{c}\text { Male group average } \\
(\mathrm{N}=20)\end{array}$ & $\begin{array}{c}\text { t-value the average } \\
\text { differences }\end{array}$ & p-value \\
\hline AL & 0.1900 & 0.3952 & -2.5005 & 0.0143 \\
\hline
\end{tabular}

Table 5. Results of the t-test of gender on the ratio of derivative asset allocation: the lowest regret bias group. This table groups the respondents by their gender (DUMMY) and regret bias $(\mathrm{RB})$. The table presents data derived from the $t$-test of the mean differences in the impacts of female and male investors on the ratio of derivative asset allocation (AL).

\begin{tabular}{ccccc}
\hline \multirow{2}{*}{ Variable } & \multicolumn{4}{c}{ Statistics (Q1) } \\
\cline { 2 - 5 } & $\begin{array}{c}\text { Female group } \\
\text { average } \\
(\mathrm{N}=18)\end{array}$ & $\begin{array}{c}\text { Male group average } \\
(\mathrm{N}=4)\end{array}$ & $\begin{array}{c}\mathrm{t} \text {-value of the average } \\
\text { differences }\end{array}$ & p-value \\
\hline AL & 0.2690 & 0.7891 & -2.6966 & 0.0143 \\
\hline
\end{tabular}

presents data derived from the t-test of gender differences on the ratio of derivative allocation in the highest regret bias group. According to the table, the average value of the female investors' derivative asset allocation was 0.0609 , whereas the average value for the male investors was 0.2636 . The difference in the average AL values between the two groups was $-0.2027(t=-1.8614, p=0.0775)$, which was significant at the $10 \%$ confidence level.

In contrast, the data in Table 6 and Table 7 provide different results. After controlling for the degree of regret bias, we found no difference between the genders with respect to the ratio of derivative asset allocation; i.e. the influence of gender on the ratio of derivative asset allocation exists only at two extremes. Therefore, we sought to determine the impacts of gender and regret bias on the allocation of capital into derivative assets. Figure 2 displays the derivative asset allocation as a function of the gender and regret bias. The trends in this graph show that in the groups with less regret bias, the male investors allocated the most capital to derivative assets, whereas in the higher regret bias group, the female investors allocated the most capital to derivative assets. Although the data in Table 6 and Table 7 show that the impact of gender differences on derivative asset allocation was not significant; on average, the male investors allocated more capital to derivative assets than the female investors did. This conclusion does not violate Hypothesis 3.

\subsection{System Estimation Model}

In this section, simultaneous equations were used as a system model. The interactive changes between the variables were observed and the results of the three hypotheses were further validated. Table 9 presents the weighted least squares regression coefficients. The three estimate models are described in detail in Section 3.3.3. Table 9 shows that the coefficient $C(2)$ verified the relationship 


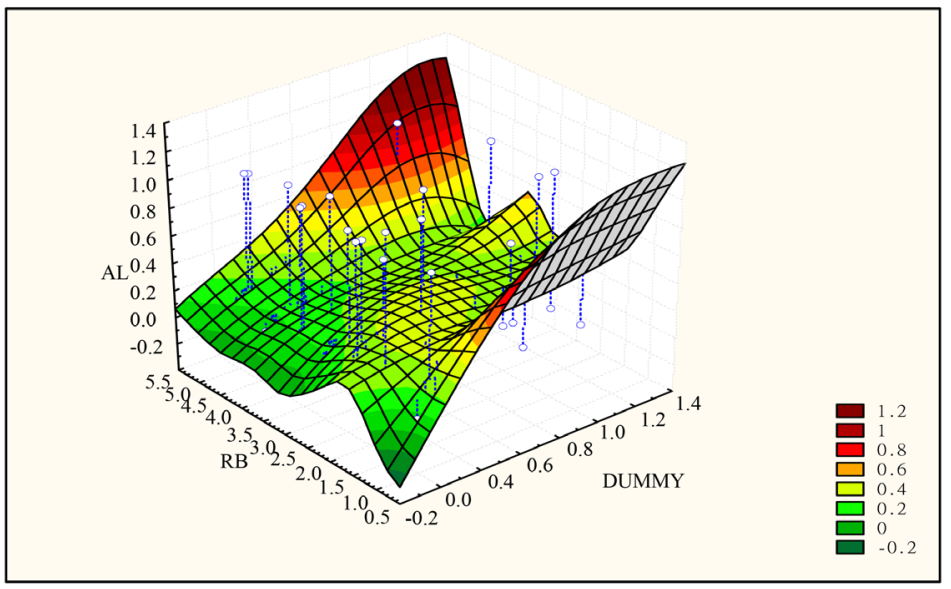

Figure 2. Surface chart of derivative asset allocation as a function of gender and regret bias. The figure displays the influence of investors with different genders and regret bias on the derivative asset allocation.

Table 6. Results of the t-test of the effects of gender on the ratio of derivative asset allocation: the second lowest regret bias group. This table groups the respondents by their gender (DUMMY) and regret bias (RB). The data show the t-test results of the mean differences between the female and male investors with respect to the derivative asset allocation ratio $(\mathrm{AL})$.

\begin{tabular}{ccccc}
\hline \multirow{2}{*}{ Variable } & \multicolumn{4}{c}{ Statistics $(\mathrm{Q} 2)$} \\
\cline { 2 - 5 } & $\begin{array}{c}\text { Female group average } \\
(\mathrm{N}=16)\end{array}$ & $\begin{array}{c}\text { Male group average } \\
(\mathrm{N}=6)\end{array}$ & $\mathrm{t}$-value of the average difference & p-value \\
\hline $\mathrm{AL}$ & 0.2373 & 0.3090 & -0.4331 & 0.6696 \\
\hline
\end{tabular}

Table 7. Results of the t-test of the effects of gender on the ratio of derivative asset allocation: the second highest regret bias group. This table groups the respondents by their gender (DUMMY) and regret bias (RB). The data show the t-test result for the mean differences between the female and male investors with respect to the derivative asset allocation ratio $(\mathrm{AL})$.

\begin{tabular}{ccccc}
\hline \multirow{2}{*}{ Variable } & \multicolumn{4}{c}{ Statistics $(\mathrm{Q} 3)$} \\
\cline { 2 - 5 } & $\begin{array}{c}\text { Female group } \\
\text { average } \\
(\mathrm{N}=17)\end{array}$ & $\begin{array}{c}\text { Male group average } \\
(\mathrm{N}=5)\end{array}$ & t-value of the average differences & p-value \\
\hline AL & 0.1953 & 0.3149 & -0.7412 & 0.4668 \\
\hline
\end{tabular}

Table 8. Results of the t-test of the effect of gender on the ratio of derivative asset allocation: the highest regret bias group. This table groups the respondents by their gender (DUMMY) and regret bias (RB). The data show the t-test results of the mean differences between the female and male investors with respect to the derivative asset allocation ratio (AL).

\begin{tabular}{ccccc}
\hline & \multicolumn{4}{c}{ Statistics (Q4) } \\
\cline { 2 - 5 } Variable & $\begin{array}{c}\text { Female group } \\
\text { average } \\
(\mathrm{N}=17)\end{array}$ & $\begin{array}{c}\text { Male group average } \\
(\mathrm{N}=5)\end{array}$ & t-value of the average differences & p-value \\
\hline $\mathrm{AL}$ & 0.0609 & 0.2636 & -1.8614 & 0.0775 \\
\hline
\end{tabular}


Table 9. Table of the regression coefficients of the weighted least squares. The results presented in this table are based on the system equations for estimating the weighted least squares (WLS) regression. The three equations for the WLS regression are as follows: Equation (1): $D E=C(1)+C(2) * R B$; Equation (2):

$T O=C(3)+C(4) * R B+C(5) * R+C(6) * R B * S R$; and Equation (3):

$A L=C(7)+C(8) * R B+C(9) * D U M M Y+C(10) * R B * D U M M Y$. R-squared of Equation $(1)=0.000975$; R-squared of Equation $(2)=0.116137$; and R-squared of Equation (3) $=0.140155 . C(1)-C(10)$ are the regression coefficients estimated by means of the system equations. For example, the coefficient $C(9)$ was +0.5090 and was significant at the $5 \%$ confidence level.

\begin{tabular}{lccc}
\hline & Coefficient & t-value & p-value \\
\hline$C(1)$ & -0.100938 & -0.644431 & 0.5199 \\
$C(2)$ & 0.013143 & 0.293086 & 0.7697 \\
$C(3)$ & 0.468506 & 2.628806 & 0.0091 \\
$C(4)$ & 0.029495 & 0.574097 & 0.5664 \\
$C(5)$ & -0.029975 & -0.510475 & 0.6102 \\
$C(6)$ & -0.010359 & -0.61091 & 0.5418 \\
$C(7)$ & 0.361014 & 3.36144 & 0.0009 \\
$C(8)$ & -0.052543 & -1.696976 & 0.0909 \\
$C(9)$ & 0.509043 & 1.98097 & 0.0487 \\
$C(10)$ & -0.086454 & -1.195976 & 0.2328 \\
\hline
\end{tabular}

between RB and DE. The coefficient was +0.0131 and did not reach a level of statistical significance, although the relationship is consistent with the predictions of prospect theory ( $\partial \mathrm{DE} / \partial \mathrm{RB}>0)$. The coefficient $C(6)$ verified the effect of the interaction of SR and RB on TO. The coefficient itself was -0.0104 , which did not reach statistical significance; however, the relationship is in agreement with the hypothesis $(\partial(\mathrm{SR} \times \mathrm{RB}) / \partial \mathrm{TO}<0)$. The coefficient $C(9)$ verified the impact of DUMMY on AL. After controlling for the two variables, i.e. RB and $\mathrm{RB} \times \mathrm{DUMMY}$, we found that the regression coefficient was $+0.5090(p<0.05)$, which conforms to Hypothesis 3 ( $\partial \mathrm{DUMMY} / \partial \mathrm{AL}>0$ ). Additionally, the coefficient $C(9)$ reached a level of statistical significance. The other regression coefficients are listed in Table 9. Figure 3 depicts the residual after estimating the system equation. Based on the changes shown in the graph, the residuals of each equation were centered about the 0 -axis. This finding shows that the estimated situation was not problematic. The system equations showed that the directions of the variables of the underlying assumptions did not change.

\section{Conclusions and Recommendations}

The purpose of this study was to explore the influences of psychological bias, social relationships and personal characteristics on trading behavior. Through descriptive statistics, t-tests and the weighted least squares regressions, several important conclusions were reached. First, Hypothesis 1 did not hold. A significant 
DE Residuals

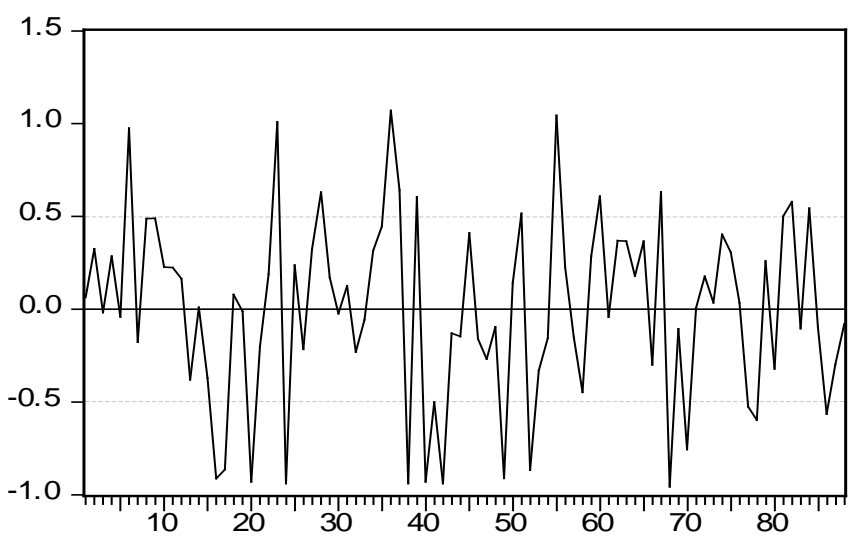

TO Residuals

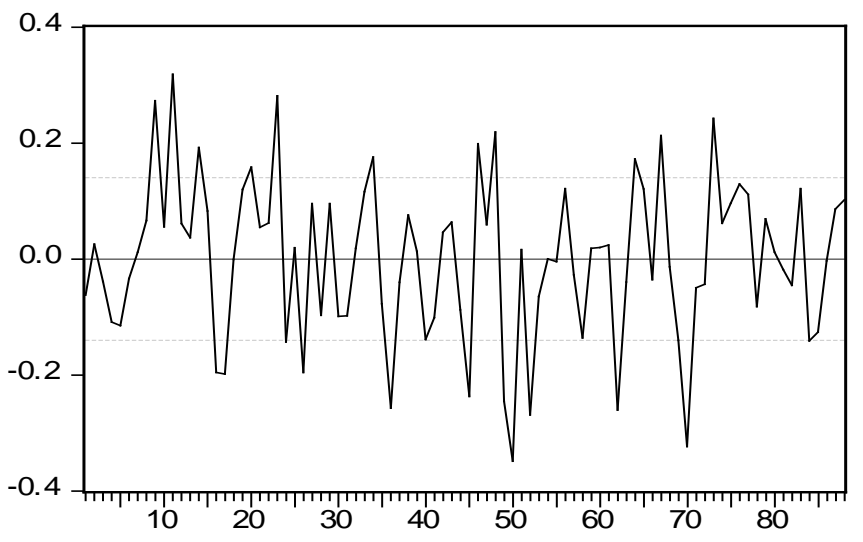

AL Residuals

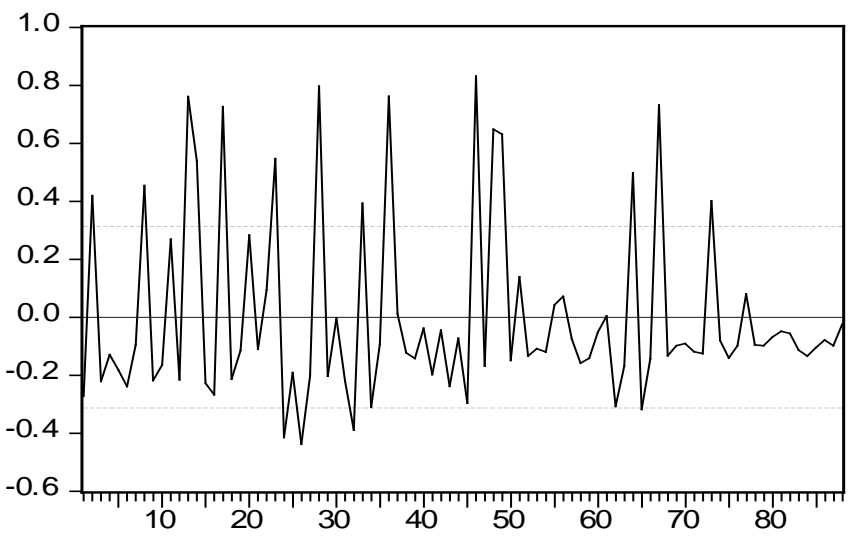

Figure 3. Residual plots after the system equations were estimated. The figure shows the residual plots after the system equations were estimated.

relationship between regret bias and the disposition effect was not observed. There are several reasons for the non-significance of these results. First, the lack of significance may be related to the professional training of the investors and the insignificance of the disposition effect, as argued by Locke and Mann [45]. 
Second, the investors with greater regret bias and better community relationships sold fewer shares of their stocks than other investors because of the contradictions arising from their decision-making processes, thus supporting Hypothesis 2. Third, Hypothesis 3 was supported. Even after controlling for regret bias, we found that male investors tended to exhibit overconfidence more often than women did and preferred to trade derivatives. In addition to supporting the findings of Arano et al. and other researchers, the conclusion implies that men have a higher degree of overconfidence than women do, and male investors make more careless investment decisions than female investors do [27] [29].

The results of this paper were derived from the observations of 40,795 transactions made by 88 investors over 6 months. Although the trading platform, trading mechanism and the amount of funds were modeled on real trading situations, there may have been certain differences between the model and the actual investment scenario. Grinblatt and Keloharju discussed several factors that may affect investors' trading behavior [46]. These factors include the reference price effect, the effect of volatility, miscellaneous stocks and investor attributes, all of which serve as determinants of sales and tax-loss selling. This study did not discuss these impact factors. Additionally, because the disposition effect was not found to be significant, the relationship between regret bias and irrational investment behavior was not confirmed. This result may have been related to the division of the investment period and the relevant variables [23] [32] [33]. In the future, we will attempt to combine these two directions to expand the research model and further study the relationship between psychological biases and irrational investment behavior.

\section{References}

[1] Barberias, N.A.S. and Vishny, R. (1998) A Model of Investor Sentiment. Journal of Financial Economics, 49, 307-343.

[2] Rildes, R. (2015) Forecasters and Rationality-A Comment on Fritsche et al., Forecasting the Brazilian Real and Mexican Peso: Asymmetric Loss, Forecast Rationality and Forecaster Herding. International Journal of Forecasting, 31, 140-143. https://doi.org/10.1016/j.ijforecast.2014.01.003

[3] Fong, K., Gallagher, D.R., Gardner, P. and Swan, P.L. (2004) A Closer Examination of Investment Manager Herding Behavior. Working Paper, University of New South Wales Press, Sydney.

[4] Hawang, S. and Salmon, M. (2004) Market Stress and Herding. Journal of Empirical Finance, 11, 585-616. https://doi.org/10.1016/j.jempfin.2004.04.003

[5] Lakonishok, J., Schleifer, A. and Vishny, R.W. (1992) Impact Institutional Trading o Stock Price. Journal of Financial Economics, 32, 23-43. https://doi.org/10.1016/0304-405X(92)90023-Q

[6] Scharfstein, D.S. and Stein, J. (1990) Herd Behavior and Investment. American Economic Review, 80, 465-479.

[7] Hong, H., Kubik, J.D. and Stein, J.C. (2004) Social Interaction and Stock-Market Participation. The Journal of Finance, 59, 137-163. https://doi.org/10.1111/j.1540-6261.2004.00629.x

[8] Shefrin, H. (2001) Do Investors Expect Higher Returns from Safer Stocks than from 
Riskier Stocks? The Journal of Psychology and Financial Markets, 2, 176-181. https://doi.org/10.1207/S15327760JPFM0204_1

[9] Tutek, H.B., Aydogan, B., Tunc, G. and Vardar, G. (2010) The Impact of Gender Differences on Financial Risk Perceptions. Iktisat Isletme ve Finans, 25, 47-70.

[10] Vlaev, I., Kusev, P., Stewart, N., Aldrovandi, S. and Chater, N. (2010) Domain Effects and Financial Risk Attitudes. Risk Analysis, 30, 1374-1386. https://doi.org/10.1111/j.1539-6924.2010.01433.x

[11] Deaves, R.E.L. and Luo, G.Y. (2009) An Experimental Test of the Impact of Overconfidence and Gender on Trading Activity. Review of Finance, 13, 555-575. https://doi.org/10.1093/rof/rfn023

[12] Kahneman, D. and Tversky, A. (1979) Prospect Theory: An Analysis of Decision under Risk. Econometrica, 47, 263-291. https://doi.org/10.2307/1914185

[13] Ahn, H.K., Kim, H.J. and Aggarwal, P. (2014) Helping Fellow Beings: Anthropomorphized Social Causes and the Role of Anticipatory Guilt. Psychological Science, 25, 224-229. https://doi.org/10.1177/0956797613496823

[14] Chong, F. (2009) Disposition Effect and Flippers in the Bursa Malaysia. Journal of Behavioral Finance, 10, 152-157. https://doi.org/10.1080/15427560903167712

[15] Goo, Y.J., Chen, D.H., Sylcien Chang, S.H. and Yeh, C.F. (2010) A Study of the Disposition Effect for Individual Investors in the Taiwan Stock Market. Emerging Markets Finance and Trade, 46, 108-119. https://doi.org/10.2753/REE1540-496X460110

[16] Oehler, A., Heilmann, K., Läger, V. and Oberländer, M. (2003) Coexistence of Disposition Investors and Momentum Traders in Stock Markets: Experimental Evidence. Journal of International Financial Markets, 13, 503-522. https://doi.org/10.1016/S1042-4431(03)00020-9

[17] Hiramatsu, A., Kurisu, K. and Keisuke, H. (2016) Environmental Consciousness in Daily Activities Measured by Negative Prompts. Sustainability, 8, 24.

[18] Daniel, K. and Titman, S. (1997) Evidence on the Characteristics of Cross-Sectional Variation in Stock Returns. Journal of Finance, 52, 1-33. https://doi.org/10.1111/j.1540-6261.1997.tb03806.x

[19] Ho, C.M. (2013) Private Information, Overconfidence, and Intraday Trading Behavior: Empirical Study of the Taiwan Stock Market. Applied Financial Economics, 23, 325-345. https://doi.org/10.1080/09603107.2012.720012

[20] Shiller, R.J. and Pound, J. (1989) Survey Evidence on Diffusion of Interest and Information among Investors. Journal of Economic Behavior, 12, 47-66. https://doi.org/10.1016/0167-2681(89)90076-0

[21] Maital, S., Filer, R. and Simon, J. (1986) What Do People Bring to the Stock Market (Beside Money)? The Economic Psychology of Stock Market Behavior. In: Gilad, B. and Kaish, S., Eds., Handbook of Behavioral Economics, Volume B, Behavioral Economics, JAI Press, Greenwich, 273-307.

[22] Finnell, J.E., Lombard, C.M., Padi, A.R., Moffitt, C.M., Wilson, L.B., Wood, C.S. and Wood, S.K. (2017) Physical versus Psychological Social Stress in Male Rats Reveals Distinct Cardiovascular, Inflammatory and Behavioral Consequences. PLoS ONE, 12, e0172868. https://doi.org/10.1371/journal.pone.0172868

[23] Tauni, M.Z., Fang, H.X. and Iqbal, A. (2017) The Role of Financial Advice and Word-of-Mouth Communication on the Association between Investor Personality and Stock Trading Behavior: Evidence from Chinese Stock Market. Personality and Individual Differences, 108, 55-65. https://doi.org/10.1016/j.paid.2016.11.048 
[24] Beyer, S. and Bowden, E.M. (1997) Gender Differences in Self-Perceptions: Convergent Evidence from Three Measures of Accuracy and Bias. Personality and Social Psychology Bulletin, 23, 157-172. https://doi.org/10.1177/0146167297232005

[25] Chen, J.H. (2010) Gender Difference and Job Replacement for Mutual Fund. Quality and Quantity, 44, 661-671. https://doi.org/10.1007/s11135-009-9228-9

[26] Deaux, K. and Emawifier, T. (1974) Explanations of Successful Performance on Sex-Linked Tasks: What Is Skill for the Male Is Luck for the Female. Journal Personal Social Psychology, 29, 80-85. https://doi.org/10.1037/h0035733

[27] Malmendier, U. and Tate, G. (2005) CEO Overconfidence and Corporate Investment. Journal of Finance, 60, 2661-2700. https://doi.org/10.1111/j.1540-6261.2005.00813.x

[28] Kulich, C., Trojanowski, G.M.K.R., Haslam, S.A. and Renneboog, L.D.R. (2011) Who Gets the Carrot and Who Gets the Stick? Evidence of Gender Disparities in Executive Remuneration. Strategic Management Journal, 32, 301-321. https://doi.org/10.1002/smj.878

[29] Arano, K.C.P. and Terry, R.L. (2010) Gender-Based Risk Aversion and Retirement Asset Allocation. Economic Inquiry, 48, 147-155. https://doi.org/10.1111/j.1465-7295.2008.00201.x

[30] Shefrin, H. and Statman, M. (1985) The Disposition to Sell Winners too Early and Ride Losers too Long: Theory and Evidence. Journal of Finance, 40, 777-790. https://doi.org/10.1111/j.1540-6261.1985.tb05002.x

[31] Choe, H. and Eom, Y. (2009) The Disposition Effect and Investment Performance in the Futures Market. Journal of Futures Market, 29, 496-522. https://doi.org/10.1002/fut.20398

[32] Ho, C.M. (2011) Does Overconfidence Harm Individual Investors? An Empirical Analysis of the Taiwanese Market. Asia-Pacific Journal of Financial Studies, 40, 658-682. https://doi.org/10.1111/j.2041-6156.2011.01053.x

[33] Odean, T. (1998) Are Investors Reluctant to Realize Their Losses? Journal of Finance, 53, 1775-1798. https://doi.org/10.1111/0022-1082.00072

[34] Shu, P.G., Yeh, Y.H., Chiu, S.B. and Chen, H.C. (2005) Are Taiwanese Individual Investors Reluctant to Realize Their Losses? Pacific-Basin Finance Journal, 13, 201-223. https://doi.org/10.1016/j.pacfin.2004.08.001

[35] Muermann, A. and Jacqueline, W.V.M. (2006) Regret, Pride, and the Disposition Effect. Working Paper. http://ssrn.com/abstract=930675

[36] Shiller, R.J. (1999) Human Behavior and the Efficiency of the Financial System. In: Taylor, J.B. and Woodford, M., Eds., Handbook of Macroeconomics, Volume 1, Chapter 20, Elsevier, Amsterdam, 1305-1340. https://doi.org/10.1016/S1574-0048(99)10033-8

[37] McGuire, W.J. (1985) Attitudes and Attitude Change. In: Lindzey, G. and Aronson, E., Eds., Handbook of Social Psychology, 3rd Edition, Vol. 2, Random House, New York, 233-346.

[38] Weber, M. and Camerer, C.F. (1998) The Disposition Effect in Securities Trading: An Experimental Analysis. Journal of Economic Behavior and Organization, 33, 167-184. https://doi.org/10.1016/S0167-2681(97)00089-9

[39] Chui, M.A. (2009) An Elective Course in Personal Finance for Health Care Professionals. American Journal of Pharmaceutical Education, 73, Article 6. https://doi.org/10.5688/aj730106

[40] Pompian, M. (2008) Behavioral Finance and Wealth Management: How to Build 
Optimal Portfolios. Wiley Finance Press, New York.

[41] Ritter, J.R. (1988) The Buying and Selling Behavior of Individual Investors at the Turn of the Year. Journal of Finance, 43, 701-717. https://doi.org/10.1111/j.1540-6261.1988.tb04601.x

[42] Amenc, N. and Sourd, L.V. (2003) Portfolio Theory and Performance Analysis. Wiley Finance Press, , New York.

[43] Hsuku, Y.H. (2007) Dynamic Consumption and Asset Allocation with Derivative Securities. Quantitative Finance, 2, 137-149. https://doi.org/10.1080/14697680601077959

[44] Greene, W.H. (2000) Econometric Analysis. Prentice Hall Press, Upper Saddle River.

[45] Locke, P.R. and Mann, S.C. (2005) Professional Trader Discipline and Trade Disposition. Journal of Financial Economics, 76, 401-444. https://doi.org/10.1016/j.jfineco.2004.01.004

[46] Grinblatt, M. and Keloharju, M. (2001) What Makes Investors Trade? The Journal of Finance, 2, 589-616. https://doi.org/10.1111/0022-1082.00338 